\title{
Chemotherapy and management of tuberculosis in the United Kingdom: recommendations 1998
}

\author{
Joint Tuberculosis Committee of the British Thoracic Society*
}

\begin{abstract}
Background-The guidelines on chemotherapy and management of tuberculosis in the United Kingdom have been reviewed and updated.

Methods-A subcommittee was appointed by the Joint Tuberculosis Committee (JTC) of the British Thoracic Society to revise the guidelines published in 1990 by the JTC. In preparing the revised guidelines the authors took account of new published evidence and graded the strength of evidence for their recommendations. The guidelines have been approved by the JTC and the Standards of Care Committee of the British Thoracic Society.
\end{abstract}

Recommendations-(1) Patients with tuberculosis should be notified. (2) In view of the rising incidence of drug resistance, bacteriological confirmation and drug susceptibility testing should be sought whenever possible. (3) A six month short course regimen, with four drugs in the initial phase, should be used for all forms of tuberculosis, except meningitis, in both adults and children. (4) The fourth drug (ethambutol) in the initial phase can be omitted in certain circumstances. (5) Treatment of all patients should be supervised by physicians with full training in the management of tuberculosis and with direct working access to tuberculosis nurse specialists or health visitors. (6) Advice is given on (a) management in special situations and patient groups, (b) drug interactions, and special precautions and pretreatment screening, (c) chemoprophylaxis for different groups, and (d) the management of single and multiple drug resistance. (7) Advice is given on follow up after treatment and the organisational framework for tuberculosis services. (8) The role of directly observed therapy is discussed. (9) The management of multidrug resistant tuberculosis is explained in outline: such patients should be managed by physicians with special experience and in close liaison with the Mycobacterium Reference Units, and in hospitals with appropriate isolation facilities. (10) Infection control and segregation for such patients and for patients with dual infection with human immunodeficiency virus (HIV) and tuberculosis are covered in an appendix.

(Thorax 1998;53:536-548)

Keywords: tuberculosis; BTS guidelines

\section{Background}

The decline in notified cases of tuberculosis in Britain, particularly in England and Wales, stopped in 1987 and was followed by an increase of some $20 \%$ between 1987 and 1990 . The numbers have since stabilised, but the trend has not been reversed. ${ }^{12}$ Over the same period there has been a moderate increase in the proportion of Mycobacterium tuberculosis isolates with single, multiple or multidrug (rifampicin and isoniazid with or without other drugs) resistance. ${ }^{34}$ In the light of these developments and the availability of new information concerning the management of tuberculosis in HIV infected persons, the Joint Tuberculosis Committee of the British Thoracic Society has updated the guidelines it issued on chemotherapy in $1990^{5}$ and on treatment of dual infection with HIV in $1992 .{ }^{6}$ Its recommendations are graded $[\mathrm{A}],[\mathrm{B}]$, and $[\mathrm{C}]$ according to the criteria shown in table 1 .

Compliance is a major determinant of the success of drug treatment-compliance of the physician in prescribing the optimum appropriate regimen and monitoring it, and compliance of the patient in taking the medication as prescribed. Drug toxicity is more likely if non-standard regimens are used and respiratory physicians are significantly more likely to prescribe the recommended standard chemotherapy ${ }^{5}$ than are clinicians from other specialities[B]. ${ }^{78}$ The JTC accordingly recommends that only physicians with full training and expertise in the management of tuberculosis and with direct working access to

Table 1 Grading of recommendations

\begin{tabular}{ll}
\hline Grade & Recommendation (based on AHCPR,1994) \\
\hline A & $\begin{array}{l}\text { Requires at least one randomised controlled trial } \\
\text { as part of the body of literature of overall good } \\
\text { quality and consistency addressing the specific } \\
\text { recommendation }\end{array}$ \\
B & $\begin{array}{l}\text { Requires availability of well conducted clinical } \\
\text { studies but no randomised clinical trials on the } \\
\text { topic of recommendation. } \\
\text { Requires evidence from expert committee reports } \\
\text { or opinions and/or clinical experience of } \\
\text { respected authorities, but indicates absence of } \\
\text { directly applicable studies of good quality }\end{array}$ \\
&
\end{tabular}

Returned to autho

Revised version received

23 December 1997

Accepted for publication

21 January 1998 
Table 2 Recommended dosages of standard antituberculosis drugs

\begin{tabular}{|c|c|c|c|c|c|c|}
\hline \multirow[b]{3}{*}{ Drug } & \multicolumn{3}{|c|}{ Daily dosage } & \multicolumn{3}{|l|}{ Intermittent dosage } \\
\hline & \multirow[b]{2}{*}{ Children } & \multicolumn{2}{|l|}{ Adults } & \multirow[b]{2}{*}{ Children } & \multicolumn{2}{|l|}{ Adults } \\
\hline & & Weight & Dose & & Weight & Dose \\
\hline Isoniazid & $5 \mathrm{mg} / \mathrm{kg}^{\star}$ & - & $300 \mathrm{mg}$ & $15 \mathrm{mg} / \mathrm{kg} 3$ times weekly & - & $15 \mathrm{mg} / \mathrm{kg} 3$ times weekly \\
\hline Rifampicin & $10 \mathrm{mg} / \mathrm{kg}$ & $\begin{array}{l}<50 \mathrm{~kg} \\
\geqslant 50 \mathrm{~kg}\end{array}$ & $\begin{array}{l}450 \mathrm{mg} \\
600 \mathrm{mg}\end{array}$ & $15 \mathrm{mg} / \mathrm{kg} 3$ times weekly & - & $600-900$ mg 3 times weekly \\
\hline Pyrazinamide & $35 \mathrm{mg} / \mathrm{kg}$ & $\begin{array}{l}<50 \mathrm{~kg} \\
\geqslant 50 \mathrm{~kg}\end{array}$ & $\begin{array}{l}1.5 \mathrm{~g} \\
2.0 \mathrm{~g}\end{array}$ & $\begin{array}{l}50 \mathrm{mg} / \mathrm{kg} 3 \text { times weekly } \\
75 \mathrm{mg} / \mathrm{kg} \text { twice weekly }\end{array}$ & $\begin{array}{l}<50 \mathrm{~kg} \\
\geqslant 50 \mathrm{~kg} \\
<50 \mathrm{~kg} \\
\geqslant 50 \mathrm{~kg}\end{array}$ & $\begin{array}{l}2.0 \mathrm{~g} \\
2.5 \mathrm{~g} 3 \text { times weekly } \\
3.0 \mathrm{~g} \\
3.5 \mathrm{~g} \text { twice weekly }\end{array}$ \\
\hline Ethambutol $^{\star \star}$ & $15 \mathrm{mg} / \mathrm{kg}$ & & $15 \mathrm{mg} / \mathrm{kg}$ & $\begin{array}{l}30 \mathrm{mg} / \mathrm{kg} 3 \text { times weekly } \\
45 \mathrm{mg} / \mathrm{kg} \text { twice weekly }\end{array}$ & & $\begin{array}{l}30 \mathrm{mg} / \mathrm{kg} 3 \text { times weekly } \\
45 \mathrm{mg} / \mathrm{kg} \text { twice weekly }\end{array}$ \\
\hline
\end{tabular}

$\star$ See text.

${ }^{\star \star}$ Accurate calculation is required to reduce the risk of toxicity (see under "Special precautions").

tuberculosis nurse specialists or tuberculosis health visitors should be responsible for the treatment of adult patients with respiratory tuberculosis [B]. The drug treatment of adult non-respiratory cases should, at the very least, be managed by such a physician who would normally be the respiratory physician of the hospital or district. Children should be managed either by a paediatrician with special experience and training in tuberculosis, or by a general paediatrician in conjunction with a suitably trained physician [B].

\section{Drugs}

Controlled trials have defined a number of highly effective short course regimens in widely varying populations of patients and health services, and the basic mechanisms of action of the major antituberculosis drugs are now better understood. ${ }^{9-11}$ Isoniazid is the most effective bactericidal drug, but rifampicin is also important. Rifampicin and pyrazinamide are the most important sterilising drugs and are thought to act by killing different populations of semidormant organisms (persisters). Isoniazid and rifampicin are the most effective drugs at preventing the emergence of resistance to other drugs. ${ }^{912}$ Streptomycin and ethambutol are weaker but nevertheless effective drugs.

Six month regimens including four drugs in the initial phase (rifampicin, isoniazid, pyrazinamide plus streptomycin or ethambutol) followed by rifampicin and isoniazid in the continuation phase are highly effective ${ }^{13-16}$ in patients with fully sensitive organisms. The need for the fourth drug (streptomycin or ethambutol) in the initial phase of chemotherapy has been questioned for such patients. Trials in Singapore ${ }^{17}$ and Poland ${ }^{18}$ have shown no loss of efficacy if streptomycin is omitted. The same is probably true of ethambutol which

Table 3 Recommended drug regimens for adults and children

\begin{tabular}{|c|c|c|c|c|c|}
\hline & \multicolumn{2}{|c|}{ Initial phase } & \multicolumn{2}{|c|}{ Continuation phase } & \multirow{2}{*}{$\begin{array}{l}\text { Total } \\
\text { months }\end{array}$} \\
\hline & Drugs & Months & Drugs & Months & \\
\hline Respiratory and non-respiratory & $\operatorname{HRZ}(\mathrm{E})$ & 2 & HR & 4 & 6 \\
\hline Meningitis/CNS & HRZ(E) & 2 & HR & 10 & 12 \\
\hline \multirow[t]{2}{*}{ Chemoprophylaxis } & $\mathrm{H}$ & 6 & & & 6 \\
\hline & HR & 3 & & & 3 \\
\hline For isoniazid resistant organisms & $\mathrm{R}$ & 6 & & & 6 \\
\hline
\end{tabular}

$\mathrm{R}=$ rifampicin $; \mathrm{H}=$ isoniazid $\mathrm{Z}=$ pyrazinamide; $\mathrm{E}=$ ethambutol.

(E) Ethambutol may be omitted in previously untreated white patients who are known to be HIV negative or thought likely to be on negative risk assessment and not contacts of a case of known drug resistance. is a less potent antituberculosis drug. Several different dosing schedules for the antituberculosis drugs (daily throughout, ${ }^{16}$ daily for two months followed by two or three times weekly for four months, ${ }^{17}$ or three times weekly from the start for six months ${ }^{19}$ ) have all been shown to be highly effective.

The dosages of antituberculosis drugs for daily and intermittent use are set out in table 2 . All first line drugs should be given as a single daily dose. Dosages may need to be recalculated for weight gain or loss. For some of the drugs the dosages are higher for intermittent treatment than for daily use.

\section{Recommended treatment for adults}

RESPIRATORY TUBERCULOSIS

A six month regimen comprising rifampicin, isoniazid, pyrazinamide, and ethambutol for the initial two months followed by rifampicin and isoniazid for a further four months is recommended as standard treatment for adult respiratory tuberculosis (including isolated pleural effusion or mediastinal lymphadenopathy), irrespective of the bacteriological status of the sputum (table 3 ). In cases where a positive culture for $M$ tuberculosis has been obtained but susceptibility results are outstanding after two months, treatment including pyrazinamide (and ethambutol) should be continued until full susceptibility is confirmed, even if this is for longer than two months. The fourth drug (ethambutol) can be omitted in patients with a low risk of resistance to isoniazid ${ }^{17}{ }^{18}$ - that is, previously untreated white patients who are known to be HIV negative or thought likely to be HIV negative on risk assessment, and who are not contacts of a patient with known drug resistant organisms. ${ }^{34}$ Individuals who are known or suspected to be HIV positive, ${ }^{3}$ who are from other ethnic groups, ${ }^{3}{ }^{4}$ or who have had previous treatment or are recent arrivals such as immigrants and refugees of any ethnic group have a significantly higher risk of resistance to isoniazid and other drugs, and should be commenced on the four drug combination unless there are very strong contraindications to the use of one of these drugs [A].

If initial pyrazinamide is not prescribed or cannot be tolerated, then the duration of treatment in adults and children should be extended to nine months and ethambutol given for the initial two months [A]. Routine daily pyridoxine is not required but should be given 
to those at increased risk of peripheral neuropathy (see later).

NON-RESPIRATORY TUBERCULOSIS

There have been fewer controlled trials in nonrespiratory tuberculosis, but the evidence suggests that nearly all forms can be treated with the six month short course regimen recommended for respiratory tuberculosis. For some forms of non-respiratory tuberculosis the duration of treatment may need to be longer than six months (see sections on meningitis and disseminated tuberculosis below).

Peripheral lymph nodes

The third BTS trial showed that a six month regimen was just as effective as the nine month regimen. ${ }^{20}{ }^{21}$ The six month regimen recommended for respiratory tuberculosis is therefore also recommended for lymph node disease [A]. The course of lymph node disease is variable; abscesses may form, nodes may enlarge, or new nodes may develop during or after treatment, without any evidence of bacteriological reactivation of disease. Such phenomena do not in themselves imply failure of treatment ${ }^{22}$ or relapse. ${ }^{23}$

Bone and joints

The spine is the commonest bony site of tuberculosis. Multicentre trials have shown that ambulatory chemotherapy is highly effective in disease of the thoracic and lumbar spine, although surgery plus chemotherapy may be required for the few patients with evidence of spinal cord compression or instability. Treatment for six months has given good results. ${ }^{24-27}$ The six month regimen used for respiratory tuberculosis is therefore recommended [A].

\section{Pericarditis}

A six month regimen of rifampicin and isoniazid, supplemented with streptomycin and pyrazinamide for three months, has been shown to be highly effective ${ }^{28}$ and the six month regimen recommended for respiratory disease should be equally effective [B]. The same trial also showed clear benefit from high dose corticosteroid treatment $(60 \mathrm{mg} /$ day initially, tailing over several weeks) in acute constrictive tuberculous pericarditis ${ }^{28}$ and for tuberculous pericardial effusion. ${ }^{29}$

\section{Meningitis}

Isoniazid, pyrazinamide, and prothionamide/ ethionamide penetrate into the cerebrospinal fluid well ${ }^{30}$; rifampicin penetrates less well. Streptomycin and ethambutol only penetrate in adequate concentrations when the meninges are inflamed in the early stage of treatment.

Intrathecal administration of streptomycin is unnecessary. There is lack of evidence from randomised trials but experience in centres treating large numbers suggests that rifampicin and isoniazid for 12 months, supplemented by pyrazinamide and a fourth drug for at least the first two months will give good results [C]. ${ }^{31}$ Corticosteroids are recommended for more severe disease (stages II and III ) ${ }^{31}$ The fourth drug in the initial phase of treatment can be streptomycin, ${ }^{31}$ ethambutol, ${ }^{31}$ or ethionamide. ${ }^{32}$ Although the risk of ocular toxicity at a dosage of $15 \mathrm{mg} / \mathrm{kg}$ is very small, ${ }^{33}$ ethambutol should be used with caution in unconscious patients (stage III) as visual acuity cannot be tested. If pyrazinamide is omitted or cannot be tolerated treatment will need to be prolonged to 18 months. For cerebral tuberculoma(s) without meningitis the 12 month regimen is still recommended $[\mathrm{C}]$.

\section{Disseminated tuberculosis}

For tuberculosis in multiple sites, or miliary disease whether classical or cryptic, ${ }^{34}$ the six month regimen is recommended unless there is clinical or laboratory evidence of central nervous system involvement when treatment should be as for meningitis (above) [C]. In view of the high rate of blood borne spread to the meninges in miliary tuberculosis, such cases require a lumbar puncture so that they are allocated the correct duration of treatment.

Other sites (including genitourinary)

The six month regimen used in respiratory tuberculosis is recommended [C].

\section{Chemotherapy for children}

In general, dosages are rounded up to facilitate the prescription of easily given volumes of syrup or appropriate strengths of tablet. Dosages may need to be re-calculated with weight gain. Supplemental pyridoxine is not necessary except for breast fed infants and malnourished children. ${ }^{35}$ Recommended dosages for isoniazid vary considerably. The International Union against Tuberculosis and Lung Diseases (IUATLD) ${ }^{37}$ and the World Health Organisation (WHO $)^{38}$ recommend $5 \mathrm{mg} / \mathrm{kg}$ up to maximum dose of $300 \mathrm{mg} /$ day. Others $^{35}{ }^{36} 6^{39-42}$ recommend $10 \mathrm{mg} / \mathrm{kg}$ up to a maximum of $300 \mathrm{mg}$ daily. Pharmacokinetic studies show that $5 \mathrm{mg} / \mathrm{kg}$ achieves serum levels 60-100 times minimum inhibitory concentration $^{43}$ and satisfactory clinical outcome is achieved $[\mathrm{B}]$. $^{43-45}$

\section{RESPIRATORY TUBERCULOSIS INCLUDING HILAR} ADENOPATHY

There is usually a history of contact with a smear positive patient. Treatment should consist of rifampicin and isoniazid for six months, supplemented by pyrazinamide for the first two months [A]. Ethambutol should also be included in the first two months if the criteria for a fourth drug recommended for adults apply to the child (see earlier). A review of the literature concluded that, for children aged five years or more, ethambutol can be recommended at a dosage of $15 \mathrm{mg} / \mathrm{kg} /$ day for routine treatment without taking any more precautions than for adults, and that for younger children ethambutol could also be used without undue fear of side effects. ${ }^{46}$ The above regimen results in close to $100 \%$ cure rate in patients with fully sensitive organisms. Children with pulmonary tuberculosis are rarely infectious as cavitatory disease is very unusual. 
MENINGITIS

This should be treated for a minimum of 12 months with rifampicin and isoniazid, with an initial two months of pyrazinamide, as well as a fourth drug which can be either streptomycin or ethambutol [C]. ${ }^{31} 32$ 40-42

\section{OTHER EXTRAPULMONARY LESIONS/SITES}

There are no controlled trials examining treatment for extrapulmonary tuberculosis in children. ${ }^{4142}$ Present recommendations are based on trials in adults. Treatment of tuberculous adenitis, bowel disease, pericarditis, bone and joint disease, and other end organ disease should be with the standard six month regimen $[\mathrm{C}]$. For disseminated and congenital tuberculosis treatment should be given for six months unless there is evidence of meningeal or other central nervous system involvement when treatment should be as for meningitis (above).

\section{Special groups}

DIABETES

Although individuals with diabetes have an increased incidence of tuberculosis, and pulmonary disease is often more extensive, ${ }^{47}$ standard treatment should be given. Rifampicin reduces the efficacy of sulphonyl ureas.

LIVER DISEASE

Although rifampicin, isoniazid and pyrazinamide are all potentially hepatotoxic, the addition of pyrazinamide to regimens containing the other two drugs does not increase morbidity. ${ }^{13}$ Baseline and regular monitoring of liver function is required in patients with known chronic liver disease such as alcoholism, chronic active hepatitis, cirrhosis, and in those known to be hepatitis B or C antigen positive. In such patients surveillance should be particularly frequent in the first two months of treatment (weekly liver function tests for the first two weeks, and then at two weekly intervals). ${ }^{48}$

\section{PREGNANCY}

Patients should be told of the reduced effectiveness of oral contraceptives if they are prescribed regimens containing rifampicin, and be given contraceptive advice. Should pregnancy occur in patients taking rifampicin, it is not an indication for termination. Standard treatment should be given to pregnant women. None of the first line drugs has been shown to be teratogenic in humans, but ethionamide and prothionamide may be teratogenic and are best avoided. Streptomycin and other aminoglycosides should be avoided in pregnancy as they may be ototoxic to the fetus. Patients can breast feed normally while taking antituberculosis drugs [C].

RENAL DISEASE

Rifampicin, isoniazid, and pyrazinamide can be given in standard dosage in renal impairment. If streptomycin or ethambutol are used, reduced doses are required and serum concen- trations should be monitored. Dialysis in patients with chronic renal failure affects the clearance of drugs and requires modifications of dose. ${ }^{49}$

\section{CORTICOSTEROIDS}

Because of enzyme induction the maintenance dose of corticosteroid taken for other conditions should be doubled if rifampicin is used. ${ }^{50}$ Corticosteroids should be given, in addition to antituberculosis treatment, for pericarditis, ${ }^{28} 29$ for stage II and III meningitis, ${ }^{31}{ }^{51}$ and for endobronchial disease in children. ${ }^{52}$ Corticosteroids may be indicated in tuberculosis affecting the ureter, ${ }^{53}$ in pleural effusions, ${ }^{54}$ in patients with extensive pulmonary disease, ${ }^{55}$ and to suppress hypersensitivity reactions to antituberculosis drugs. ${ }^{55}$

\section{UNCONSCIOUS PATIENTS}

Standard chemotherapy should be given to unconscious patients. Isoniazid and rifampicin can be given as syrup, and pyrazinamide as syrup or crushed tablets, administered by nasogastric or enteral feeding tube (for dosages see table 2). Alternatively, rifampicin (Rifadin infusion) and isoniazid (Rimifon) can be administered by once daily intravenous infusion. Isoniazid can also be given by intramuscular injection. Streptomycin is given intramuscularly.

\section{HIV POSITIVE PATIENTS}

The classical type of tuberculosis with upper zone pulmonary disease tends to occur less commonly in those patients with a very low CD4 lymphocyte count, who are more likely to have disseminated tuberculosis. The mortality in patients with dual tuberculosis/HIV infection is higher than in HIV negative patients. ${ }^{56} 57$ In HIV infected individuals there have been no controlled trials of sufficient power to detect differences in efficacy between regimens. A small clinical study suggests that standard regimens, particularly if supervised properly, are as effective in HIV positive as in HIV negative patients. ${ }^{58}$

The principles for infection control for tuberculosis in HIV infected persons, recommended since the most recent control and prevention guidelines from the JTC, ${ }^{59}$ are summarised in the Appendix. ${ }^{60}$

Patients with HIV related tuberculosis should be given the standard four drug regimen unless multidrug resistant tuberculosis is suspected. It has been recommended that antituberculosis treatment should be continued for longer in patients with HIV infection ${ }^{6}$ than in those without, but there is little evidence to support this for those with fully sensitive organisms. ${ }^{61}$ If cultures remain positive after three months, compliance and drug absorption need detailed assessments. Tuberculosis treatment should be under the management of an appropriately qualified specialist. (For drug resistance, particularly multidrug resistant tuberculosis, additional advice is given later on pp 544-6). 
Table 4 Adverse reactions to the main antituberculosis drugs

\begin{tabular}{|c|c|c|c|}
\hline Drug & Common reactions & Uncommon reactions & Rare reactions \\
\hline Isoniazid & & $\begin{array}{l}\text { Hepatitis } \\
\text { Cutaneous hypersensitivity } \\
\text { Peripheral neuropathy }\end{array}$ & $\begin{array}{l}\text { Giddiness } \\
\text { Convulsion } \\
\text { Optic neuritis } \\
\text { Mental symptoms } \\
\text { Haemolytic anaemia } \\
\text { Aplastic anaemia } \\
\text { Sideroblastic anaemia } \\
\text { Agranulocytosis } \\
\text { Lupoid reactions } \\
\text { Arthralgia } \\
\text { Gynaecomastia }\end{array}$ \\
\hline Rifampicin & & $\begin{array}{l}\text { Hepatitis } \\
\text { Cutaneous reactions } \\
\text { Gastrointestinal reactions } \\
\text { Thrombocytopenic } \\
\text { purpura } \\
\text { Febrile reactions } \\
\text { 'Flu-syndrome'^ }\end{array}$ & $\begin{array}{l}\text { Shortness of breath }{ }^{\star} \\
\text { Shock } \\
\text { Haemolytic anaemia } \\
\text { Acute renal failure }\end{array}$ \\
\hline Pyrazinamide & $\begin{array}{l}\text { Anorexia } \\
\text { Nausea } \\
\text { Flushing }\end{array}$ & $\begin{array}{l}\text { Hepatitis } \\
\text { Vomiting } \\
\text { Arthralgia } \\
\text { Hyperuricaemia } \\
\text { Cutaneous hypersensitivity }\end{array}$ & $\begin{array}{l}\text { Gout } \\
\text { Photosensitisation }\end{array}$ \\
\hline Ethambutol & & $\begin{array}{l}\text { Retrobulbar neuritis } \\
\text { Arthralgia }\end{array}$ & $\begin{array}{l}\text { Hepatitis } \\
\text { Cutaneous hypersensitivity } \\
\text { Peripheral neuropathy }\end{array}$ \\
\hline
\end{tabular}

* Much more common with intermittent than with daily therapy.

Modified from Chan SL, in Clinical tuberculosis (Davies PDO, ed), 1994, Chapman Hall, London with permission.

Table 5 Drug interactions of the main antituberculosis drugs

\begin{tabular}{|c|c|c|c|c|}
\hline Drug & $\begin{array}{l}\text { Level } \\
\text { increased by }\end{array}$ & $\begin{array}{l}\text { Level } \\
\text { decreased by }\end{array}$ & Increases level of & Decreases level of \\
\hline Isoniazid & $\begin{array}{l}\text { Prednisolone } \\
\text { Ethionamide }\end{array}$ & - & $\begin{array}{l}\text { Phenytoin } \\
\text { Carbamezepine } \\
\text { Warfarin } \\
\text { Diazepam }\end{array}$ & $\begin{array}{l}\text { Enflurane } \\
\text { Azoles }\end{array}$ \\
\hline Pyrazinamide & - & - & Probenecid & - \\
\hline Ethambutol & - & $\mathrm{Al}(\mathrm{OH})_{3}$ & - & - \\
\hline Rifampicin & - & $\begin{array}{l}\text { PAS } \\
\text { Ketoconazole }\end{array}$ & - & $\begin{array}{l}\text { Warfarin } \\
\text { Other azoles } \\
\text { Sulphonylureas } \\
\text { Oral contraceptives } \\
\text { Glucocorticoids } \\
\text { Phenytoin } \\
\text { Diazepam } \\
\text { Theophyllines } \\
\text { Vitamin D } \\
\text { Digitoxin } \\
\text { Methadone } \\
\text { Protease inhibitors } \\
\text { Cyclosporin }\end{array}$ \\
\hline
\end{tabular}

Modified from Winstanley PA, in Clinical tuberculosis (Davies PDO, ed), 1994, Chapman Hall, London with permission. rising. ${ }^{62}$ The United States Centers for Disease Control recommends that DOT be considered for all patients, but that if more than $90 \%$ of the patients in an area are completing selfadministered treatment, selective DOT (in unreliable patients) is an alternative [B]. ${ }^{65}$ In practice, some $15 \%$ of patients in the USA receive DOT, and recent decision analyses suggest that both selective and universal DOT policies are cost effective when compared with conventional therapy. ${ }^{66-68}$

In the UK, where tuberculosis is (or should be) treated by experienced physicians working closely with tuberculosis health visitors or nurses, DOT is recommended for patients who are unlikely to comply. These include patients who are homeless, alcoholic or drug abusers, drifters, seriously mentally ill, patients with multiple drug resistances, and for those with a history of non-compliance with antituberculosis medication, either in the past or documented during treatment monitoring [C] ${ }^{69}$ DOT should also be considered for new immigrants/refugees.

A hospital based DOT clinic, meeting patients' medical and social needs, was superior to a residence based or homeless shelter based programme in a depressed inner city population in New York which included many patients at risk of non-compliance. ${ }^{70}$ The elements of a successful programme include accessible clinics, good staff/patient relations, free drugs, and skilled nurses. These features are already present in chest clinics so that clinic based DOT may be most appropriate for the $\mathrm{UK}^{71}$ In registered methadone users with tuberculosis, medication can be given by the community pharmacist or clinic staff supervising the supply and consumption of methadone. ${ }^{72}$ In such patients the dose of methadone may need to be temporarily increased because rifampicin increases methadone clearance. ${ }^{73}$ One possible means of DOT would be to ask a responsible person to be a "medication monitor", an approach which relies on a strong family or community structure. $^{74}$

DOT can be daily but an intermittent regimen is often more convenient (table 2). A regimen of rifampicin, isoniazid and pyrazinamide, with either streptomycin or ethambutol, three times weekly for two months, followed by rifampicin and isoniazid three times weekly for a further four months is recommended for those with sensitive organisms [A]. An adequately resourced local structure for the provision of selective DOT should be in place in all districts [C].

There may occasionally be conflict between civil liberty and public health. Whilst compulsory admission and detention is possible under Sections 37 and 38 of the Public Health Act (but only for infectious tuberculosis of the respiratory tract), compulsory treatment is not allowed so that a collaborative rather than a coercive approach is indicated, with compulsory admission only being sought in extreme circumstances in order to safeguard the public health. 
Adverse reactions and interactions

All antituberculosis drugs may cause adverse reactions. Reactions occurred in $10 \%$ of patients treated for pulmonary and lymph node tuberculosis in $1993^{78}$ with a substantial proportion of them requiring modification of drug therapy. Reactions were significantly more common in those not receiving standard chemotherapy. ${ }^{5}$ The most important adverse reactions are set out in table 4 and interactions in table 5 (for full details of all possible adverse reactions and interactions the appropriate summary of product characteristics should be consulted).

Peripheral neuropathy from isoniazid is preventable by pyridoxine $10 \mathrm{mg}$ daily, but this is advised only for those at increased risk of neuropathy-for example, diabetics, alcoholic or HIV positive patients and those with chronic renal failure or malnutrition.

Shock, acute renal failure, and thrombocytopenic purpura may occur rarely with rifampicin, usually with intermittent treatment; if so withdraw the drug and do not reintroduce. The corticosteroid dose should be doubled ${ }^{50}$ for patients on maintenance corticosteroids who are starting on rifampicin.

Reactions to antituberculosis drugs are more common in HIV positive individuals ${ }^{61}$ in whom life threatening adverse events occur occasionally with any antimycobacterial regimen, but especially with thiacetazone. Rifampicin and isoniazid can interact with azole antifungal drugs, reducing serum concentrations of fluconazole and itraconazole to suboptimal levels. ${ }^{75-77}$ Ketoconazole can inhibit rifampicin absorption if taken at the same time, possibly leading to failure of antituberculosis treatment. ${ }^{75}$

Many HIV positive patients are now started on combination anti-HIV drugs including protease inhibitors. Protease inhibitors are metabolised by the CYP 3A P450 enzyme, an enzyme induced by rifampicin. Patients treated for tuberculosis may therefore experience a significant but variable decrease even to undetectable levels of protease inhibitor drugs. ${ }^{77} 78$ Patients who are on protease inhibitors or in whom they are being considered have three main options ${ }^{79}:$ (1) to discontinue the protease inhibitor and use alternative antiretroviral drugs until the tuberculosis has been treated; (2) to omit rifampicin from the regimen and extend treatment to 18 months $^{79}$; and (3) to use indinavir as the protease inhibitor and substitute rifabutin (in a reduced dosage) for rifampicin. Although rifabutin has been shown to be effective in some small studies of treatment of tuberculosis, ${ }^{80} 81$ we recommend that the first option be pursued whenever possible $[\mathrm{C}]$.

\section{Special precautions and pretreatment screening}

(1) Because of the possible (but rare) toxic effects of ethambutol on the eye, it is recommended that visual acuity should be tested by Snellen chart ${ }^{33}$ before it is first prescribed. The drug should only be used in patients who have reasonable visual acuity and who are able to appreciate and report visual symptoms or changes in vision. The notes should record that the patient has been told to stop the drug immediately if such symptoms occur, and to report to the physician. The general practitioner should also be informed of this. In small children and in those with language difficulties ethambutol should be used where appropriate, with the above advice given to parents or other family members.

(2) Renal function should be checked before treatment with either streptomycin or ethambutol. If possible these drugs should be avoided in renal failure, but if they are used serum drug concentrations should be monitored and substantially reduced dosages given unless dialysis is used.

(3) Liver function should be checked before treatment for clinical cases. Detailed advice on the monitoring of liver function and management of hepatotoxicity has recently been published $^{48}$ which can be summarised as follows:

- Patients and general practitioners should be informed of possible side effects and indications for stopping medication and seeking advice.

- Regular monitoring of liver function, weekly for two weeks then two weekly for the first two months, is required for patients with known chronic liver disease.

- Regular monitoring of liver function is not required for those with no evidence of pre-existing liver disease and normal pretreatment liver function. Liver function should be repeated (and treatment stopped) if fever, malaise, vomiting, jaundice, or unexplained deterioration occur.

- Virological tests to exclude coexistent viral hepatitis should be considered.

- Modest elevations of hepatic transaminases (ALT/AST) are not uncommon in the pretreatment liver functions tests of tuberculosis patients.

- If the AST/ALT are two or more times normal, liver function should be monitored weekly for two weeks, then two weekly until normal.

- If the AST/ALT is under two times normal, liver function should be repeated at two weeks. If transaminase levels have fallen, further repeat tests are only required for symptoms. If the repeat test shows an AST/ ALT level above twice normal, management should be as above.

- If the AST/ALT level rises to five times normal or the bilirubin level rises, rifampicin, isoniazid and pyrazinamide should be stopped.

- If the patient is not unwell and the form of tuberculosis is non-infectious, no treatment needs to be given until liver function returns to normal.

- If the patient is unwell or the sputum smear positive within two weeks of commencing treatment, some form of drug treatment, preferably as an inpatient, needs to be given until liver function is normal. Streptomycin and ethambutol with appropriate checks should be used unless clinically contraindicated or drug resistance is known/suspected. 
If other reserve drugs are used, any potential hepatotoxicity should be considered.

- Once liver function is normal challenge dosages of the original drugs can be reintroduced sequentially in the order: isoniazid, rifampicin, pyrazinamide with daily monitoring of the patient's clinical condition and liver function. Isoniazid should be introduced initially at $50 \mathrm{mg} /$ day, increasing sequentially to $300 \mathrm{mg} /$ day after 2-3 days if no reaction occurs, and then continued. After a further 2-3 days without reaction rifampicin at a dose of $75 \mathrm{mg} /$ day can be added, increasing to $300 \mathrm{mg}$ after 2-3 days, and then to $450 \mathrm{mg}(<50 \mathrm{~kg}$ ) or $600 \mathrm{mg}$ $(\geqslant 50 \mathrm{~kg})$ as appropriate for the patient's weight after a further 2-3 days without reaction, and then continued. Finally, pyrazinamide is added at $250 \mathrm{mg} /$ day, increasing to $1.0 \mathrm{~g}$ after $2-3$ days and then to $1.5 \mathrm{~g}$ $(<50 \mathrm{~kg})$ or $2 \mathrm{~g}(\geqslant 50 \mathrm{~kg})$.

- If there is no further reaction standard chemotherapy can be continued and any alternative drugs introduced temporarily can then be withdrawn.

- If there is a further reaction the offending drug should be excluded and a suitable alternative regimen used. Such an alternative regimen should be on the advice of, and under the supervision of, a fully trained physician. If pyrazinamide is found to be the offending drug, treatment will need to be continued for nine months with rifampicin and isoniazid, supplemented with ethambutol for the initial two months.

- Occasionally the choice of drugs is so limited-for example, by drug resistant organisms - that if reactions occur, desensitisation and reintroduction of the offending drug may be necessary, using conventional protocols. ${ }^{82}$ To avoid the emergence of drug resistance during densensitisation the procedure must be carried out under the cover of two other antituberculosis drugs.

\section{Combined drug preparations}

Some combined drug preparations are available. Rifinah (Hoechst Marion Roussel) and Rimactazid (Novartis) combine isoniazid and rifampicin, and Rifater (Hoechst Marion Roussel) combines isoniazid, rifampicin and pyrazinamide. These rifampicin-containing preparations provide a useful means of checking compliance as the urine can be assessed visually or checked in the laboratory for orange/pink colouration. The bioavailability of drugs from such combination tablets is similar to that from the same doses of drugs given individually $^{84}$ and clinical results are satisfactory. ${ }^{85}$ The dosages of isoniazid, rifampicin and pyrazinamide in some studies of combined preparations ${ }^{84}{ }^{85}$ have varied slightly from the dosages in the currently available Rifater in the UK (50 mg isoniazid, $120 \mathrm{mg}$ rifampicin, and $300 \mathrm{mg}$ pyrazinamide per tablet). These minor variations are not thought to be clinically important in combined preparations of proven bioavailability. Care must be taken in the writing and dispensing of prescriptions because of the similarity in the names of rifampicin, Rifinah, Rimactazid, Rifadin, Rimifon, and Rifater. For patients on daily therapy combination tablets should be used whenever possible to aid compliance and to help prevent accidental monotherapy, thereby helping prevent the emergence of drug resistance [C].

\section{Chemotherapy for tuberculous infection} (chemoprophylaxis)

It is important to differentiate between infection and disease. In tuberculous infection the tuberculin skin test is positive, the chest radiograph is normal, and the patient asymptomatic. In tuberculous disease the skin test is usually positive and there are clinical signs and symptoms or radiographic changes present. $^{35}$ Asymptomatic, tuberculin positive patients with normal chest radiographs (infection) are usually treated (chemoprophylaxis) with either one drug for six months or, alternatively, with two drugs for three months. ${ }^{51}$ Infection, in contrast to disease, implies the presence of small numbers of tubercle bacilli in the body. ${ }^{41}$ The administration of one or two antituberculosis drugs for a shorter period of time than for disease (chemoprophylaxis) is likely to kill these organisms, preventing possible progression to disease at a later date. Many studies have shown that chemoprophylaxis with isoniazid for 12 months is highly effective $^{86}$ and that six months is probably as effective $[\mathrm{A}] .^{87}$

Regimens of rifampicin and isoniazid lasting only three months have been used in clinical practice in some areas of the United Kingdom with good effect and no increased adverse reactions, ${ }^{88}$ and have been shown to be as good as six months of treatment with isoniazid in a randomised controlled trial in Hong Kong $[B]{ }^{89}$ In contacts of an isoniazid resistant patient, rifampicin for six months has been shown to be effective. ${ }^{90}$

CHILDREN (UNDER 16): FOUND AT NEW IMMIGRANT OR CONTACT SCREENING

Chemoprophylaxis is recommended if, in the presence of a normal chest radiograph, the Heaf test is positive (grades 2-4) in a child without previous BCG vaccination, and should be considered if the test is strongly positive (grade 3-4) in a child who has had BCG vaccination. ${ }^{57}$ The equivalent Mantoux positive levels (Mantoux done with $10 \mathrm{TU} ; 0.1 \mathrm{ml}$ of $100 \mathrm{TU} / \mathrm{ml}$ i.e. $1: 1000)$ ) are $5-14 \mathrm{~mm}$ induration (Heaf 2) and $>15 \mathrm{~mm}$ induration (Heaf 3-4), respectively. ${ }^{91}$ If the chest radiograph proves abnormal, standard chemotherapy should be given and the child's disease notified.

Recommended chemoprophylaxis: either isoniazid alone for six months or rifampicin and isoniazid for three months [B].

\section{TUBERCULIN POSITIVE CHILDREN IDENTIFIED IN} THE BCG SCHOOLS PROGRAMME

Tuberculin testing is not necessary in those with a definite BCG scar. ${ }^{59}$ No action is required for those with Heaf grade 2 positive. ${ }^{92}$ Children with Heaf grades 3 and 4 should be referred for clinical and radiographic 
examination. If these are normal, chemoprophylaxis is recommended for those with a history of contact with infectious tuberculosis or residence in a high prevalence country (annual prevalence $>40 / 100000$ ) within the previous two years, and should be considered for others in high risk groups. ${ }^{59}$

CHILDREN AGED UNDER 2 YEARS IN CLOSE CONTACT WITH SMEAR POSITIVE PULMONARY TUBERCULOSIS

Those without prior BCG vaccination

Such children should be placed on chemoprophylaxis irrespective of the initial tuberculin test result. If the initial tuberculin test is negative (grade 0-1) this should be repeated at six weeks and, if negative, together with a normal chest radiograph, chemoprophylaxis can be stopped and BCG vaccination given. If the repeat tuberculin test has become positive (Heaf grade 2-4) then full chemoprophylaxis should be given. If the initial tuberculin test is positive (Heaf 2-4) full chemoprophylaxis should be given. If the chest radiograph is abnormal, then standard chemotherapy is indicated.

\section{Those with prior BCG vaccination}

If the initial tuberculin test is strongly positive (Heaf 3-4) then full chemoprophylaxis should be given. If the initial tuberculin test (Heaf $0-2)$ is consistent with the BCG history, confirmed by characteristic scar or vaccination record, this should be repeated at six weeks. If it has become positive (Heaf 3-4) full chemoprophylaxis should be given if the chest radiograph is normal, or full chemotherapy if the chest radiograph is abnormal. If there is no change in the reaction to the repeat tuberculin test and the chest radiograph is normal, no further action is required.

NEONATES

Newborn babies of mothers with sputum smear positive pulmonary tuberculosis should be given isoniazid chemoprophylaxis for three months, and then tuberculin (Heaf or Mantoux) tested. If this is negative, and provided that the mother is no longer infectious, chemoprophylaxis can be stopped and BCG vaccination given. If the tuberculin test is positive without evidence of disease, then isoniazid should be continued to a total of six months. If there is evidence of disease-that is, clinical signs or an abnormal chest radiograph-full chemotherapy should be given.

\section{ADULTS}

Those in whom recent tuberculin conversion has been documented should receive chemoprophylaxis, using the same regimens as above. ${ }^{59}$ Chemoprophylaxis should also be considered for young adults aged 16-34 years who are Heaf grade 3-4 positive without BCG history and found at new immigrant screening. ${ }^{59}$

HIV POSITIVE INDIVIDUALS

The identification of individuals at high risk of developing tuberculosis is complicated in HIV infection by the loss of response to tuberculin skin test. Also the diagnosis of active tuberculosis is complicated by atypical radiological changes. Although there is a consensus from the WHO and IUATLD that individuals with dual tuberculosis/HIV infection should be given preventive therapy, ${ }^{93}$ data from clinical trials are limited. Trials examining this policy from developing countries which show short term benefit also highlight the logistical difficulties of implementing such a policy. ${ }^{94}{ }^{95} \mathrm{~A}$ recently published study from the $\mathrm{USA}^{96}$ did not support isoniazid prophylaxis in HIV infected high risk patients with anergy unless they had been exposed to active tuberculosis. Increasing rates of drug resistance and the occurrence of multidrug resistant tuberculosis in HIV infected individuals has been reported mainly in the USA..$^{97}$ In the light of the difficulties of differentiating disease from infection, widespread single drug prophylaxis carries an increased risk of the development of drug resistance. Close clinical monitoring rather than chemoprophylaxis is therefore recommended until more data are available [B]. However, if there is a history of recent contact with a smear positive index patient, assessment for clinical disease should be carried out and, if no disease found, chemoprophylaxis given with indefinite follow up.

The previous guidelines ${ }^{6}$ suggested that HIV positive patients who successfully complete a course of antituberculous chemotherapy might take prolonged, perhaps lifelong, preventive therapy - for example, with isoniazid alone - in order to prevent relapse or reinfection. ${ }^{6}$ No data have so far emerged to support such a policy in the UK and, in view of the concerns over single drug prophylaxis in HIV positive persons, routine isoniazid prophylaxis after the cessation of short course chemotherapy is therefore no longer recommended [C].

CHEMOPROPHYLAXIS FOR MULTIDRUG RESISTANT TUBERCULOSIS

This is described later under "Multidrug resistant tuberculosis".

\section{Clinical management of tuberculosis}

The minimum requirements are described here.

\section{NOTIFICATION}

All cases must be notified as this is a statutory requirement ${ }^{34}$ and initiates contact tracing if appropriate $[\mathrm{A}] .^{59}$

TREATMENT

Because of the rising incidence of drug resistant tuberculosis, it is vital to confirm the diagnosis bacteriologically whenever possible and to obtain drug susceptibilities. ${ }^{3}$ In those with respiratory disease unable to produce sputum this may involve bronchoscopy and bronchial washings or lavage, or gastric lavage in children, and biopsy specimens from extrapulmonary sites for culture as well as histological examination. Specimens for microbiological culture must not be placed in formalin or similar agents. 
Table 6 Reserve drugs: dosages and side effects

\begin{tabular}{|c|c|c|c|}
\hline Drug (once daily) & Children & Adults & Main side effects \\
\hline $\begin{array}{l}\text { Streptomycin } \\
\text { Amikacin } \\
\text { Capreomycin } \\
\text { Kanamycin }\end{array}$ & $\begin{array}{l}15 \mathrm{mg} / \mathrm{kg} \\
15 \mathrm{mg} / \mathrm{kg}\end{array}$ & $\begin{array}{l}15 \mathrm{mg} / \mathrm{kg} \text { (max dose } 1 \mathrm{~g} \text { daily) } \\
15 \mathrm{mg} / \mathrm{kg} \\
15 \mathrm{mg} / \mathrm{kg} \\
15 \mathrm{mg} / \mathrm{kg}\end{array}$ & $\begin{array}{l}\text { Tinnitus, ataxia, vertigo, renal impairment } \\
\text { As for streptomycin } \\
\text { As for streptomycin } \\
\text { As for streptomycin }\end{array}$ \\
\hline Ethionamide or prothionamide & $15-20 \mathrm{mg} / \mathrm{kg}$ & $\begin{array}{l}<50 \mathrm{~kg}, 375 \mathrm{mg} \text { bd } \\
\geqslant 50 \mathrm{~kg}, 500 \mathrm{mg} \mathrm{bd}\end{array}$ & Gastrointestinal; hepatitis; avoid in pregnancy \\
\hline Cycloserine & & $250-500 \mathrm{mg} \mathrm{bd}$ & Depression: fits \\
\hline $\begin{array}{l}\text { Ofloxacin } \\
\text { Ciprofloxacin }\end{array}$ & & $\begin{array}{l}400 \mathrm{mg} \mathrm{bd} \\
750 \mathrm{mg} \mathrm{bd}\end{array}$ & $\begin{array}{l}\text { Abdominal distress, headache, tremulousness } \\
\text { As ofloxacin plus drug interactions }\end{array}$ \\
\hline $\begin{array}{l}\text { Azithromycin } \\
\text { Clarithromycin }\end{array}$ & & $\begin{array}{l}500 \mathrm{mg} \\
500 \mathrm{mg} \text { bd }\end{array}$ & $\begin{array}{l}\text { Gastrointestinal upset } \\
\text { As for azithromycin }\end{array}$ \\
\hline Rifabutin & & $300-450 \mathrm{mg}$ & $\begin{array}{l}\text { As for rifampicin; uveitis can occur with drug } \\
\text { interactions e.g. macrolides. Often cross resistance with } \\
\text { rifampicin }\end{array}$ \\
\hline Thiacetazone & $4 \mathrm{mg} / \mathrm{kg}$ & $150 \mathrm{mg}$ & $\begin{array}{l}\text { Gastrointestinal, vertigo, conjunctivitis, rash. AVOID if } \\
\text { HIV positive (Stevens-Johnson syndrome) }\end{array}$ \\
\hline Clofazimine & & $300 \mathrm{mg}$ & Headache, diarrhoea, red skin discolouration \\
\hline PAS sodium & $300 \mathrm{mg} / \mathrm{kg}$ & $10 \mathrm{~g}$ om or $5 \mathrm{~g}$ bd & Gastrointestinal, hepatitis, fever, rash \\
\hline
\end{tabular}

Tuberculosis, pulmonary or extrapulmonary, is an AIDS defining illness. HIV testing, with informed consent and counselling, should be considered if a risk assessment shows the patient to be from an area or background with increased risk of HIV co-infection.

Most patients do not require admission to hospital and can be treated and supervised as outpatients. If an HIV negative patient is admitted to hospital, and sputum is smear positive for acid-fast bacilli, segregation for reasons of infectiousness is generally only required for two weeks. Such patients become non-infectious within two weeks of treatment. ${ }^{1198}$ Different criteria apply in the control of infection in HIV positive patients and those with multidrug resistant tuberculosis (see Appendix).

Follow up should be at least monthly initially and then two monthly, with early follow up being important to reinforce education of the patient. If the patient's progress is unsatisfactory or compliance is in doubt, sputum examination should be repeated two months before treatment is due to be stopped. A chest radiograph should be taken at the end of treatment. Monitoring of extrapulmonary disease is largely based on clinical assessment and radiography where appropriate. Tuberculosis specialist nurses or tuberculosis health visitors have very important roles in monitoring patients' compliance with treatment and the accuracy and continuity of prescribing [C]. Tablet checks and urine tests for rifampicin should be carried out at least monthly throughout chemotherapy.

Failure during chemotherapy or relapse after treatment in patients prescribed an effective regimen is almost invariably due to poor compliance (see below) which may also have induced drug resistance. A single drug must never be added to an apparently failing regimen. Failure during chemotherapy must be assumed to be due at least in part to drug resistance to some or all of the drugs. Repeat cultures and susceptibility tests should be car- ried out, and consideration given to molecular tests for rifampicin resistance. If rifampicin resistance is found treatment should be as for multidrug resistant tuberculosis (pp 545-6). The addition of a single drug in the presence of regimen failure is only likely to add to drug resistance. Patient management should be discussed with an experienced clinician. If new drugs are added this should be at least two, and preferably three, which the patient has not previously received (table 6 ). Treatment after this point should be fully supervised throughout.

DRUG RESISTANCE

Treatment of patients with drug resistant tuberculosis should only be carried out by specialist physicians with appropriate experience in the management of such cases. Initial drug resistance is uncommon $(<2 \%)$ in previously untreated white patients born in the UK. ${ }^{34}$ Higher levels of resistance occur in ethnic minority groups, particularly those of Indian subcontinent and Black African ethnic origin, with isoniazid resistance occurring in $4-6 \%$ of such patients. HIV positivity, independent of ethnic group, is also a marker for increased drug resistance, a positive HIV result increasing at least fourfold the chances of single or multiple drug resistance compared with an HIV negative individual. ${ }^{3}$

\section{Isolated resistances}

(1) Streptomycin resistance. Some of the drug resistance encountered, particularly in ethnic minority groups, is to streptomycin alone. This is not clinically important since streptomycin is rarely used ${ }^{7}$ and the efficacy of the regimen recommended for both respiratory and nonrespiratory tuberculosis is not affected [A].

(2) Isoniazid resistance. At least $4-6 \%$ of non-white patients, and a significant proportion of those who are HIV positive, have isoniazid resistant organisms which is why it is particularly important to include ethambutol as a fourth drug in the initial phase for such patients. If isoniazid resistance is known about 
before treatment is started, a regimen of rifampicin, pyrazinamide, ethambutol, and streptomycin for two months, followed by rifampicin and ethambutol for seven months has been shown to give good results if fully supervised $[\mathrm{A}] .{ }^{99}$ If definite pretreatment resistance to isoniazid is reported after the start of recommended chemotherapy, isoniazid may be stopped, but ethambutol $(15 \mathrm{mg} / \mathrm{kg})$ and rifampicin should be given for a minimum of 12 months, together with pyrazinamide for two months [C].

Although there is some evidence that the standard regimen may be effective, ${ }^{100}$ we consider it safer practice to stop isoniazid and change the regimen as above.

(3) Pyrazinamide resistance. $M$ bovis is naturally resistant to pyrazinamide. If the infecting organism is found to be $M$ bovis but is not resistant to any other drugs, treatment should be with rifampicin and isoniazid for nine months, supplemented by two month's initial ethambutol [A]. Isolated pyrazinamide resistance to $M$ tuberculosis is uncommon but should be treated with the same regimen as for $M$ bovis.

(4) Ethambutol resistance. Isolated ethambutol resistance is also uncommon; if the organism is otherwise susceptible, the six month regimen of rifampicin and isoniazid supplemented by two months' initial pyrazinamide is satisfactory [A].

(5) Rifampicin resistance. Isolated rifampicin resistance is very uncommon but does occur and requires modification and extension of treatment to a period of 18 months - that is, two months of treatment with isoniazid, pyrazinamide, and ethambutol followed by isoniazid plus ethambutol for an additional 16 months [C]. In the majority of cases, however, rifampicin resistance is a marker for multidrug resistant tuberculosis (approximately 90\%; F Drobniewski, personal communication). The patient should therefore be treated as for multidrug resistant tuberculosis until the full susceptibilities are established. Rifampicin resistance in $M$ tuberculosis cultures can be successfully determined at the PHLS Mycobacterium Reference Units using molecular methods which allow the rapid detection of rifampicin resistance in approximately $95 \%$ of those who are later proven to be resistant by conventional methods. ${ }^{101-103}$ Techniques to determine rifampicin resistance in primary specimens such as sputum are becoming available $\mathrm{e}^{104}$ but should be used only as a guide-that is, treatment with a rifampicinbased regimen should continue but with two or three additional drugs added until full susceptibilities are known.

Combined resistances

(1) Streptomycin and isoniazid resistance. Combined streptomycin and isoniazid resistance is the commonest dual resistance. Management should be as for isoniazid resistance found after treatment has commenced but with treatment fully supervised throughout $[\mathrm{A}]$.

(2) Other combinations. Other combinations are uncommon. Treatment needs to be individualised depending on the combination involved, and is best determined after discussion with a highly experienced clinician and the PHLS Mycobacterium Reference Units [C].

(3) Multidrug resistant tuberculosis. This is defined as resistance to rifampicin and isoniazid with or without resistance to other antituberculosis drugs. Treatment is complex, time consuming, and demanding for both the patient and the physician. Such treatment should only be carried out by physicians with substantial experience in managing complex resistant cases, and only in hospitals with appropriate isolation facilities, and in very close liaison with the National PHLS and Scottish Mycobacterium Reference Units and PHLS Regional Centres for Mycobacteriology [B]. ${ }^{102} 103105$ This may require transfer of the patient to an appropriate unit. Treatment of such patients has to be planned on an individual basis ${ }^{106} 107$ and needs to include reserve drugs (table 6). Such treatment must be closely monitored because of increased toxicity but, more importantly, full compliance is essential to prevent the emergence of further drug resistance so all such treatment must be directly observed throughout, both as an inpatient and an outpatient [B].

Treatment should start with five or more drugs to which the organism is, or is likely to be, susceptible and continued until sputum cultures become negative [B]. Drug treatment then has to be continued with at least three drugs to which the organism is susceptible on in vitro testing for a minimum of nine further months and perhaps up to or beyond 24 months, depending on the in vitro drug resistance profile, the available drugs, ${ }^{107}$ and the patient's HIV status. Consideration may also have to be given to resection of pulmonary lesions under drug cover. ${ }^{107}$

For infection control issues in multidrug resistant tuberculosis see Appendix.

The management of close contacts of patients with multidrug resistant tuberculosis who fulfil the criteria for chemoprophylaxis should be supervised by the designated tuberculosis physician. This applies to HIV positive and HIV negative contacts. If chemoprophylaxis is given because the contact is deemed likely to have been recently infected with multidrug resistant tuberculosis, it should include at least two and preferably three drugs chosen on the knowledge of the drug susceptibility pattern of the index case, although if the resistance pattern is extensive there may be no suitable chemoprophylaxis regimen. There are no data on how long such chemoprophylaxis should be taken, but a minimum of six months would be sensible. If the drug susceptibility pattern is not known then giving ofloxacin or ciprofloxacin with pyrazinamide has been suggested. ${ }^{108}$ The United States Centers for Disease Control suggest this combination or ethambutol and pyrazinamide. ${ }^{109}$ In some of the recent outbreaks in the UK chemoprophylaxis for multidrug resistant tuberculosis was not possible because it was either inappropriate from the drug susceptibility patterns or was not tolerated by the patients because of the toxicity 
of the drugs available (Drs P Easterbrook and A de Ruiter, personal communication). An alternative strategy, which is recommended until more data are available, is regular clinic follow up of individual cases without chemoprophylaxis [C].

\section{AFTER TREATMENT}

In the UK, when the recommended regimen has been given to patients with fully susceptible organisms, relapse is uncommon $(0-3 \%)$ if there has been good compliance with treatment. ${ }^{16}$ If compliance has been good and there are no residual clinical problems, follow up is not therefore required but the patient and the general practitioner should be advised of the need for re-referral should symptoms recur [B]. Relapse after recommended chemotherapy when compliance is thought to have been good is almost always with fully susceptible organisms and can be retreated with the same regimen. If poor compliance is thought to be a factor in relapse, a fully supervised regimen should be used.

The development of acquired resistance should be treated as described above. Those with drug resistant organisms (excluding isolated streptomycin resistance) should be followed up for at least 12 months after cessation of drug therapy, and those with multidrug resistant tuberculosis, particularly if HIV positive, should be followed up long term.

The organisational framework for the monitoring of tuberculosis treatment already exists in local respiratory medical (chest) clinics with trained doctors and nurses; treatment therefore will normally be supervised by respiratory physicians. The Joint Tuberculosis Committee confirms its opinion that a minimum of one full time equivalent tuberculosis nurse specialist or tuberculosis health visitor is required for every 50 notifications per annum, with full clerical support to monitor and deliver treatment and, in addition, to provide the control and prevention aspects of tuberculosis. ${ }^{57110}$

\section{Appendix: Infection Control in Health Care facilities for (A) tuberculosis and HIV and (B) multidrug resistant tuberculosis}

(A) Tuberculosis and HIV

The general principles for tuberculosis infection control in relation to HIV infection can be summarised as follows. ${ }^{60}$

1. A risk assessment of nosocomial tuberculosis transmission should be made, including specialist engineering advice, for all patient care areas, and there should be a tuberculosis infection control plan.

2. Suspected or confirmed pulmonary tuberculosis cases should be considered as potentially infectious on every admission until proved otherwise, and segregated appropriately from other patients, taking into account their potential infectiousness, any known or suspected drug resistance, and the immune status of other patients on the same ward.

3. Potentially infectious tuberculosis patients should not be seen in the same outpatient clinic as immunocompromised patients (including HIV).

4. Patients with potentially infectious tuberculosis should be isolated from immunocompromised patients by admission to a single room in/on a separate ward or a negative pressure ventilation room. If there are other immunocompromised patients in the same or contiguous wards, air pressure should be continuously and automatically monitored.

5. A nursing system to reduce staff exposure should be employed. Where respiratory protection is recommended, a programme with regular audit and education should be in place.

6. Aerosol generating procedures should only be carried out in an appropriately engineered and ventilated area for all patients on an HIV ward, and for suspected tuberculosis in other wards.

7. Tuberculosis treatment should be under the management of an appropriately qualified specialist. For drug resistance, particularly multidrug resistant tuberculosis, additional advice is given (see below and pp 545-6).

8. Tuberculosis patients should remain in appropriate isolation until assessed to be non-infectious (see below), or discharged home.

9. Each tuberculosis case must be judged on its merits, and the designated tuberculosis physician be involved in the decision to end isolation. The following criteria that a patient is non-infectious in an HIV setting are suggested, but it is recognised that exceptions may occur:

(i) Sputum microscopy positive cases

(a) the patient has had a mimimum of two weeks of appropriate drug therapy; and

(b) if potentially being moved to accommodation (inpatient or home) with HIV positive or immunocompromised patients to have a minimum of three negative sputum microscopy smears on separate occasions over at least a 14 day period; and

(c) demonstrated tolerance to the prescribed treatment and an ability and agreement to adhere to treatment; and either

(d) a complete resolution of cough; or

(e) definite clinical improvement to treatment e.g. remaining afebrile for one week.

(ii) Negative sputum microscopy cases (three sputum samples on separate days or if no sputum and bacteriology only from bronchoscopy/lavage), (a), (c), (d) and (e) as above apply.

\section{(B) Multidrug resistant tuberculosis}

The general principles of infection control for multidrug resistant tuberculosis are:

1. All patients with known or suspected infectious pulmonary multidrug resistant tuberculosis should be admitted to a negative pressure ventilated room. If none are available locally the patient should be transferred to a hospital where the facilities are available.

2. The same infection control assessments should be made as for HIV and tuberculosis. 
3. Staff and visitors should wear dust/mist masks e.g. PFR 95 (Technol) during patient contact while the patient is considered potentially infectious.

4. The patient should remain in isolation in a negative pressure room until assessed to be non-infectious. This involves the same criteria as for those with HIV and tuberculosis but may also include maintaining isolation until cultures are negative.

5. The decision to discharge must be discussed with the hospital infection control team, the local microbiologist, and consultant in Communicable Disease/ Public Health Medicine.

6. Before a discharge from hospital is made, secure arrangements for the supervision and administration of all antituberculosis therapy should have been made and agreed with the patient and carers.

7. All treatment as either an inpatient or an outpatient should be fully supervised unless there are exceptional circumstances.

1 Watson JM, Fern KJ, Porter JDH, et al. Notification of tuberculosis in England and Wales 1982-9. Comm Dis Report 1990;1:R13-15.

2 Hayward AC, Watson JM. Tuberculosis in England and Wales 1982-93: notifications exceeded predictions. Comm Dis Report 1995;5:R29-33.

3 Hayward AC, Bennett DE, Herbert J, et al. Risk factors for drug resistance in patients with tuberculosis in England and Wales 1993-94. Thorax 1996;51(Suppl 3):S32.

4 Kumar D, Watson JM, Charlett A, et al. Tuberculosis in England and Wales in 1993: results of a national survey. Thorax 1997; 52: 1060-7.

5 Joint Tuberculosis Committee of the British Thoracic Society. Chemotherapy and management of tuberculosis in the United Kingdom: recommendations of the Joint the United Kingdom: recommendations of the Joint Tuberculosis Commite
Thorax 1990;45:403-8.

6 Subcommittee of the Joint Tuberculosis Committee. Guidelines on the management of tuberculosis and HIV infecton in the United Kingdom. BMF 1992;304:1231-3.

7 Ormerod LP, Bentley C for the Joint Tuberculosis Committee of the British Thoracic Society. The management of pulmonary tuberculosis in England and Wales in 1993. F Roy Coll Phys Lond 1997; 31: 662-5.

8 Ormerod LP, Bentley C for the Joint Tuberculosis Committee of the British Thoracic Society. Management of lymph node tuberculosis in England and Wales in 1993. f Roy Coll Phys Lond 1997;31: 666-8.

9 Girling DJ. The chemotherapy of tuberculosis. In: Ratle C, Stanford J, Grange JM, eds. Biology of mycobacteria - clinical aspects of mycobacteria. Vol 3. London: Academic Press, 1989: 285-323.

10 Mitchison DA. Treatment of tuberculosis. $\mathcal{f} R$ Coll Phys 1980:14:91-9.

11 Jindani A, Aber VR, Edwards EA, et al. The early bactericidal activity of drugs in patients with pulmonary tuberculosis. Am Rev Respir Dis 1980;121:139-48.

12 Anonymous. Chemotherapy of pulmonary tuberculosis in Britain. Drug Ther Bull 1988;26:1-4.

13 British Thoracic Association. A controlled trial of 6-months chemotherapy in pulmonary tuberculosis. First report: results during chemotherapy. $B r f$ Dis Chest 1981:75:141-153.

14 Singapore Tuberculosis Service and British Medical Research Council. Clinical trial of six-month and fourmonth chemotherapy in the treatment of pulmonary month chemotherapy in the treatment of pulmonary
tuberculosis. The results up to 30 months. Tubercle 1981;62:95-102.

15 East and Central African and British Medical Research Council. Clinical controlled trial of four short-course regimens of chemotherapy (three six-month, and one eightmonth)

16 British Thoracic Society. A controlled trial of six-months chemotherapy in pulmonary tuberculosis. Final report: results during the 36 months after the end of chemotherapy and beyond. Br F Dis Chest 1984:78:330-6.

17 Singapore Tuberculosis Service and British Medical Research Council. Clinical trial of three 6-month regimens of chemotherapy given intermittently in the continuation phase in the treatment of pulmonary tuberculosis. Am Rev Respir Dis 1985;132:374-8.

18 Snider DE, Graczyk DE, Bek E, et al. Supervised six-months treatment of newly diagnosed pulmonary tuberculosis using isoniazid, rifampin and pyrazinamide tuberculosis using isoniazid, rifampin and pyrazinamide
with or without streptomycin. Am Rev Respir Dis 1984;130:1091-4.
19 Prabhakar R. Fully intermittent six-month regimens for pulmonary tuberculosis in South India. In: Proceedings of the XXVI World IUAT Conference, Singapore. Professional Postgraduate Services, Japan, 1987:21-3.

20 British Thoracic Society Research Committee. Six months versus nine months chemotherapy for tuberculosis of lymph nodes:preliminary results. Respir Med 1992;86:159.

21 Campbell IA, Ormerod LP, Friend JAR, et al. Six months versus nine months chemotherapy for tuberculosis of lymph nodes:final results. Respir Med 1993;87. 621-3.

22 Campbell IA, Dyson AJ. Lymph node tuberculosis:a comparison of various methods of treatment. Tubercle $1977 ; 58$ : $171-9$

23 Campbell IA, Dyson AJ. Lymph node tuberculosis:a comparison of treatments 18 months after completion of parison of treatments 18 months

24 Girling DJ, Darbyshire JH, Humphries MJ, et al. Extra-pulmonary tuberculosis. Br Med Bull 1988;44:73856.

25 Medical Research Council Working Party on Tuberculosis of the Spine. A controlled trial of 6-month and 9-month regimens of chemotherapy in patients undergoing radical surgery for tuberculosis of the spine in Hong Kong. Tubercle 1986;67:243-59.

26 Medical Research Council Working Party on Tuberculosis of the Spine. Controlled trial of short-course regimens of chemotherapy in ambulatory treatment of spinal tuberculosis. F Bone foint Surg 1993;75:240-8.

27 Indian Council of Medical Research/British Medical Research Council Working Party. A controlled trial of short-course regimens of chemotherapy in patients receiving ambulatory treatment or undergoing radical surgery for tuberculosis of the spine. Ind $\mathcal{F}$ Tuberc 1989;36(Suppl): $1-22$.

28 Strang JIG, Kakaka HHS, Gibson DG, et al. Controlled trial of prednisolone as an adjuvant in treatment of tuberculous constrictive pericarditis in Transkei. Lancet 1987;ii: $1418-22$.

29 Strang JIG, Kakaka HHS, Gibson DG, et al. Controlled clinical trial of complete open surgical drainage and of prednisolone in treatment of tuberculous pericardial effusion in Transkei. Lancet 1988;ii:759-63.

30 Ellard GA, Humphries MJ, Gabriel M, et al. Penetration of pyrazinamide into the CSF in tuberculous meningitis. BMF 1985;294:284-5.

31 Humphries $M$. The management of tuberculous meningitis. Thorax 1992;47:577-81.

32 Donald PR, Seifart HI. Cerebrospinal fluid concentrations of ethionamide in children with tuberculous meningitis. 7. Pediatr 1989;115:383-6.

33 Citron KM, Thomas GO. Ocular toxicity from ethambutol. Thorax 1986;41:737-9.

34 Ormerod LP, Watson JM, Pozniak A, et al. Notification of tuberculosis: an updated code of practice for England and Wales. F R Coll Phys 1997:31:299-303.

35 American Academy of Pediatrics. Tuberculosis. In: Peter $\mathrm{G}$, ed. 1994 Red Book Report of the Committee on Infectious Diseases. 23rd edn. Elk Grove Village, IL. American Academy of Pediatrics, 1994: 480-500.

36 American Academy of Pediatrics, Committee on Infectious Diseases. Chemotherapy for tuberculosis in infants and children. Pediatrics 1992;89:161-5.

37 International Union against Tuberculosis and Lung Disease. Antituberculosis regimens of chemotherapy. Recommendation from the committee on treatment of IUATLD. Bull Int Union Tuberc Lung Dis 1988;63:60-4.

38 World Health Organisation Tuberculosis Unit. Division of Communicable Diseases. Guidelines for tuberculosis treatment in adults and children in national treatment programmes. WHO Geneva, 1991: WHO/tuberculosis/91:1 61.

39 Grange JM. Antimycobacterial agents. In: O'Grady F, Lambert HP, Finch RG, Greenwood D, eds. Antibiotics and chemotherapy. 7th edn. Churchill Livingstone, 1997: 499-512.

40 American Thoracic Society. Treatment of tuberculosis and tuberculosis infection in adults and children. Am F Respir Crit Care Med 1994;149:1359-74.

41 Jacobs RF, Eisenach KD. Childhood tuberculosis. Adv Pediatr Infect Dis 1993;8:23-51.

42 Inselman L. Tuberculosis in children: an update. Pediatr Pulmonol 1996;21:101-20.

43 Roy V, Tekur U, Chopra K. Pharmacokinetics of isoniazid in pulmonary tuberculosis: a comparative study at two in pulmonary tuberculosis: a comparative

44 Mazouni SM. Short-course chemotherapy (6 months) for respiratory tuberculosis in children: results at 30 months. Bull Int Union Tuberc 1986;61:16-17.

45 Palma Beltran OR, Pelosi F, Budani H, et al. The treatment of child tuberculosis with isoniazid $(\mathrm{H})$, rifampicin $(\mathrm{H})$ and pyrazinamide (Z). Bull Int Union Tuberc 1986;61:17.

46 Trebucq A. Should ethambutol be recommended for routine treatment of tuberculosis in children? A review of the literature. Int $\mathcal{F}$ Tuberc Lung Dis 1997;1:12-15.

47 Hendy M, Stableforth D.E. The effect of established diabetes mellitus on the presentation of infiltrative pulmonary tuberculosis in the immigrant asian community of an inner city area of the United Kingdom. $\mathrm{Br} \mathcal{F}$ Dis Chest 1983;77:87-9.

48 Ormerod LP, Skinner C, Wales JM. Hepatotoxicity of antituberculosis drugs. Thorax 1996;51:111-3.

49 Anonymous. Tuberculosis in patients having dialysis (editorial). BMF 1980;1:349. 
50 Edwards OM, Courtney-Evans RJ, Galley JM, et al. Changes in cortisol metabolism following rifampicin Changes in cortisol metabolism

51 Schoerman JF, Van Zyl LE, Laubscher JA, et al. Effects of corticosteroids on intracranial pressure, computed tomographic findings, and clinical outcome in young children with tuberculous meningitis. Pediatrics 1997;99:226-31.

52 Toppet M, Malfroot A, Derde MP, et al. Corticosteroids in primary tuberculosis with bronchial obstruction Arch Dis Child 1990;65:1222-6.

53 Horne NW, Tulloch WS. Conservative management of renal tuberculosis. Br f Urol 1975;47:481-7.

54 Lee CH. Wang WJ, Lan RS, et al. Corticosteroids in the treatment of tuberculous pleurisy. A double blind, placebo controlled, randomized study. Chest 1988;94:1256-9.

55 Horne NW. A critical evaluation of corticosteroids in tuberculosis. Adv Tuberc Res 1966;15:1-54.

56 Grosset JH. Treatment of tuberculosis in HIV infection. Tuberc Lung Dis 1992;73:378-83.

57 Ackah AN, Coulibaly D, Digbeu $\mathrm{H}$, et al. Response to treatment, mortality, and CD4 lymphocyte counts in HIVinfected persons with tuberculosis in Abidjan, Cote d'Ivoire. Lancet 1995;345:607-10.

58 Perriens JH, St.Louis ME, Yiadiul B, et al. Pulmonary tuberculosis in HIV-infected patients in Zaire. N Engl Med f 1995;332:779-84

59 Joint Tuberculosis Committee of the British Thoracic Society. Control and prevention of tuberculosis in the United Kingdom: code of practice 1994. Thorax 1994;49: 1193-200.

60 Interdepartmental Working Group on Tuberculosis. United Kingdom recommendations for the prevention and control of HIV-related tuberculosis and drug-resistant, including multiple drug-resistant, tuberculosis. Consultaincluding multiple drug-resistant, tuberculosis. Consult

61 Small PM, Schecter GF, Goodman PC, et al. Treatment of tuberculosis in patients with advanced human immunodetuberculosis in patients with advanced human immunode-
ficiency virus infection. $N$ Engl f Med 1990:324:289-94.

62 Morse DI. Directly observed therapy for tuberculosis. Morse DI. Directly obs
$B M \mathcal{F} 1996 ; 312: 719-20$.

63 China Tuberculosis Control Collaboration Results of directly observed short-course chemotherapy in 112,842 Chinese patients with smear-positive tuberculosis, Lance 1996;347:358-62.

64 Caminero JA, Pavon JM, Rodriguez de Castro F, et al. Evaluation of a directly observed six month fully intermittent treatment regimen for tuberculosis in patients suspected of poor compliance. Thorax 1996;51:1130-3.

65 Centers for Disease Control. Initial therapy for tuberculosis in the era of multidrug resistance: recommendations of the advisory council for the elimination of tuberculosis. MMWR Morb Mortal Wkly Rep 1993;42:RR-7.

66 Moore RD, Chaulk CP, Griffiths R, et al. Costeffectiveness of directly observed versus self administered therapy for tuberculosis. Am $\mathcal{F}$ Respir Crit Care Med 1996; 154:1013-9.

67 Sbarbaro JA. The ultimate decision analysis:the confirmation of reality through theory. Am 7 Respir Crit Care Med tion of reality thro

68 Miller B, Palmer CS, Halpern MT, et al. Decision model to assess the cost-effectiveness of DOT for tuberculosis. Tuberc Lung Dis 1996;77(Suppl 2):74-5.

69 Sumartojo E. When tuberculosis treatment fails:a social behavioural account of patient adherence. Am Rev Respir Dis 1993;147:1311-20.

70 Schluger N, Ciotoli C, Cohen D, et al. Comprehensive tuberculosis control for patients at high risk for noncompliance. Am f Respir Crit Care Med 1995;151:1486-90.

71 Rolfe LM, Millard FJC, Rayner CFJ. A programme of directly observed therapy for tuberculosis in London. Tho$\operatorname{rax}$ 1996;51(Suppl 3):A32.

72 Sell L, Finch E, Farrell M, et al. Directly observed treatment for tuberculosis. BMF 1996;313:45.

73 Raistrick D, Hay A, Wolff K. Methadone maintainance and tuberculosis treatment. BMF 1996;313 925-6.

74 Chowdhury AMR, Chowdury S, Islam MN, et al. Control of tuberculosis by community health workers in Bangladesh. Lancet 1997;350:169-72.

75 Englehard D, Stutman HR, Marks MI. Interaction of ketoconazole with rifampicin and isoniazid. $N$ Engl Med $\mathcal{F}$ 1994;311:1681-3

76 Lazar JD, Wilner KD. Drug interactions with fluconazole. Rev Infect Dis 1990;12(Suppl 3):S327-333.

77 Heyden R, Miller R. Adverse effects and drug interactions of medications commonly used in the treatment of adult HIV positive patients. Genitourinary Med 1996;72;237-46.

78 Heyden R, Miller R. Adverse effects and drug interactions of medications commonly used in the treatment of adult HIV positive patients: Part 2. Geniturinary Med 1997;73:511.

79 Anonymous. Clinical update. Impact of HIV protease inhibitors on the treatment of HIV-infected tuberculosis patients with rifampicin. MMWR 1996;45:921-5.

80 McGregor MM, Olliaro P, Wolramans L, et al. Efficacy and safety of rifabutin in the treatment of patients with newly safety of rifabutin in the treatment of patients with newly
diagnosed pulmonary tuberculosis. Am $\mathcal{f}$ Respir Crit Care Med 1996;154:1462-7.
81 Bass JB, Farer LS, Hopewell PC, et al. Treatment of tuberculosis and tuberculosis infection in adults and children. culosis and tuberculosis infectic

82 Davies PDO, Girling DJ, Grange JM. Tuberculosis. In: Weatherall DJ, Ledingham JGG, Orrell DJ, eds.Oxford textbook of medicine. 3rd edn. Oxford: Oxford Medical Publications, 1995: 638-661.

83 Horne NW. Modern drug treatment of tuberculosis. 7th edn. London: Chest Heart and Stroke Association, 1990: 32-5.

84 Ellard GA, Ellard DR, Allen BW, et al. The bioavailability of isoniazid, rifampin and pyrazinamide in two comercially available combined formulations designed for use in shortcourse therapy in tuberculosis. Am Rev Respir Dis 1986:133:1076-80.

85 Geiter LJ, O’Brien RJ, Coombs DL, et al. United States Public Health Service tuberculosis therapy trial 21. Preliminary results of an evaluation of a combination tablet of isoniazid, rifampin and pyrazinamide. Tubercle 1987; 68:41-6.

86 Ferebee SH. Controlled chemoprophylaxis trials in tuberculosis. A general review. Adv Tuberc Res 1970;17:28-104.

87 Thomson NJ. Efficacy of various durations of isoniazid preventive therapy in tuberculosis: 5 years of follow-up in the IUAT trial. Bull WHO 1982;60:555-64.

88 Ormerod LP. Rifampicin and isoniazid prophylaxis for tuberculosis. Arch Dis Child 1998;78: 169-71.

89 Hong Kong Chest Service/Tuberculosis Research Centre Madras/ British Medical Research Council. A doubleblind placebo-controlled clinical trial of three antituberculosis chemoprophylaxis regimens in patients with silicosis in Hong Kong. Am Rev Respir Dis 1992;145:3641 .

90 Polesky A, Forber HW, Gotlieb DJ, et al. Rifampin preventive therapy for tuberculosis in Boston's homeless. Am $\mathcal{F}$ Respir Crit Care Med 1996;154:1473-7.

91 Departments of Health. Immunisation against infectious disease. London: HMSO, 1996: 232.

92 Outbreak Forum IV. High prevalence of tuberculin sensitivity. Commun Dis Rep 1992;1:R67-9.

93 IUATLD, GPA (WHO). Tuberculosis preventive therapy in HIV infected individuals; a joint statement of the IUATLD and GPA (WHO). Tuberc Lung Dis 1994;75:96-

94 Fitzgerald JM. The downside of isoniazid chemoprophylaxis. Lancet 1995;345:404

95 Aisu T, Raviglione MC, Van Praag E, et al. Preventive chemotherapy for HIV associated tuberculosis in Uganda: an operational assessment of a voluntary counselling and testing centre. AIDS 1995;9:267-73.

96 Gordin FM, Matts JP, Miller C, et al. A controlled trial of isoniazid in persons with anergy and human immunodeficiency virus infection who are at high risk for tuberculosis. N Engl f Med 1997;337:315-20.

97 Neville K, Bromberg A, Bromberg R, et al. The third epidemic: multidrug resistant tuberculosis. Chest 1994; 105:45-8.

98 Rouillon A, Predizet S, Parrot R. Transmission of tubercle bacilli. The effects of chemotherapy. Tubercle 1976;57:27599.

99 Babu Swai O, Alnoch JA, Githui WA, et al. Controlled clinical trial of a regimen of two durations for the treatment of isoniazid resistant tuberculosis. Tubercle 1988;69:5-14.

100 Mitchison DA, Nunn AJ. Influence of initial drug resistance on the response to short-course chemotherapy in pulmonary tuberculosis. Am Rev Respir Dis 1986;133: $423-30$.

101 Telenti A, Imboden P, Marchesi F, et al. Detection of rifampicin-resistance mutation in Mycobacterium tuberculosis. Lancet 1993;341:647-50.

102 Drobniewski FA, Kent RJ, Stoker NG, et al. Molecular biology in the diagnosis and epidemiology of tuberculosis. f Hosp Infect 1994;28:249-63.

103 Drobniewski FA, Pozniak AL. Molecular diagnosis, detection of drug resistance and epidemiology of tuberculosis. Br f Hosp Med 1996;56:204-8.

104 Goyal M, Shaw RJ, Banerjee DK, et al. Rapid detection of multidrug-resitant tuberculosis. Eur Respir F 1997;10:1204.

105 Drobniewski FA. Is death inevitable with multiresistant tuberculosis plus HIV infection? Lancet 1997;349:71-2.

106 Goble M, Iseman M, Madsen LA, et al. Treatment of 171 patients with pulmonary tuberculosis resistant to isoniazid and rifampin. N Engl F Med 1993;328:527-32.

107 Iseman $M$. Treatment of multidrug-resistant tuberculosis. N Engl F Med 1993;329:784-90.

08 Gallagher CT, Passannante MR, Reichman LB. Preventive therapy for multidrug resistant tuberculosis (MDRtuberculosis):a Delphi survey. Am Rev Respir Dis 1992;145: Abstract.

109 Anonymous. Management of persons exposed to multidrug resistant tub

110 Interdepartmental Working Group on Tuberculosis. Recommendations for the control and prevention of tubercu-
losis at a local level. Department of Health and Welsh Office. June 1996, 30. 